Research Paper

\title{
Bifidobacterium pseudocatenulatum CECT 7765 supplementation restores altered vascular function in an experimental model of obese mice
}

María D. Mauricio ${ }^{1,2} \llbracket$, Eva Serna ${ }^{3 *}$, María Leonor Fernández-Murga ${ }^{4}$, Jesica Portero ${ }^{3}$, Martín Aldasoro ${ }^{1,2}$, Soraya L. Valles ${ }^{1,2}$, Yolanda Sanz ${ }^{4}$, José M. Vila1,2

1. Departamento de Fisiología, Universitat de Valencia, Valencia, Spain;

2. Fundación de Investigación del Hospital Clínico Universitario de Valencia/INCLIVA, Valencia, Spain

3. Unidad Central de Investigación. Facultad de Medicina, Universitat de Valencia, Valencia, Spain;

4. Microbial Ecology, Nutrition and Health Research Group, Institute of Agrochemistry and Food Technology, National Research Council (IATA-CSIC), Valencia, Spain.

* These authors contributed equally to this work and share first authorship.

$\triangle$ Corresponding author: Maria D. Mauricio. Department of Physiology. School of Medicine. University of Valencia. Blasco Ibañez, 15. 46010 Valencia, Spain. Phone: 34-963983950. Fax: 34-96-3864642. Email: m.dolores.mauricio@uv.es

(C) Ivyspring International Publisher. This is an open access article distributed under the terms of the Creative Commons Attribution (CC BY-NC) license (https://creativecommons.org/licenses/by-nc/4.0/). See http://ivyspring.com/terms for full terms and conditions.

Received: 2016.11.15; Accepted: 2017.01.30; Published: 2017.04.08

\begin{abstract}
Aims. Bifidobacterium pseudocatenulatum CECT 7765 improves metabolic and immunological altered functions in high fat fed mice, however little is known about the effects of potential probiotics on vascular reactivity. The aim of the present study was to investigate the effects of a potential probiotic strain, Bifidobacterium pseudocatenulatum CECT 7765, on vascular response in obese mice.

Methods. Aorta samples were obtained from mice, which were divided into three groups: a control group, receiving a standard diet; an obese group, receiving a high-fat diet; and an obese group receiving high-fat diet and a daily dose of $B$. pseudocatenulatum CECT 7765 by oral gavage. Aortic rings were suspended in organ baths for isometric recording of tension. mRNA expression of eNOS was evaluated by real-time polymerase chain reaction.

Results. Contractions induced by $\mathrm{KCl}$, noradrenaline and thromboxane analogue were $33 \%, 30 \%$ and $45 \%$ lower respectively in aortic rings from obese mice. Bifidobacteria administration reversed this effect. eNOS inhibition increased the response to noradrenaline in the three groups with a significant lower magnitude in aortic rings from obese mice receiving bifidobacteria supplement. Acetylcholine caused a greater vasodilation in aorta from obese group $(46 \pm 3 \%$ for control and $69 \pm 4 \%$ for obese group; $\mathrm{p}<0.05)$ and bifidobacteria reversed it $(57 \pm 5 \%)$. Response to sodium nitroprusside was displaced 2.9 times to the left in a parallel manner in obese group. Relaxation to sodium nitroprusside remained unchanged in the bifidobacteria fed group. There was about five-fold decreased mRNA expression of eNOS in aortic segments from the group receiving bifidobacteria.
\end{abstract}

Conclusion. Bifidobacterium pseudocatenulatum CECT 7765 restores the obesity-induced altered vascular function mainly by reducing nitric oxide release.

Key words: Bifidobacterium, nitric oxide, obesity, vascular reactivity.

\section{Introduction}

Obesity, a chronic multifactorial disease of high prevalence in industrialized and developing countries, is characterized by an excessive accumulation of body fat as result of a positive energy imbalance between energy intake and expenditure. In addition, obesity is also associated with a chronic 
inflammatory process, oxidative stress, and affects vascular smooth muscle response [1]. Diet plays a primary role in obesity and also in modulating the gut microbiota structure, suggesting that the role of microbes in energy balance is under the influence of diet. Accordingly, modulation of the gut microbiota via administration of probiotic bacteria such as specific strains of bifidobacteria has been proposed as a potential strategy to aid in the prevention and treatment of obesity [2-4]. In particular, Bifidobacterium pseudocatenulatum CECT 7765 has been shown to improve metabolic and immunological alterations associated with obesity in mice [5-7]. Obesity is considered one of the risk factors associated with atherosclerosis and vascular dysfunction [8,9]. Vascular homeostasis is regulated by endothelium that modulates the tone of blood vessels through the release of relaxing factors, such as (NO), and contractile factors, such as endothelin-1 (ET-1) and cyclooxygenase (COX) derived products as endoperoxides or thromboxane $\mathrm{A}_{2}\left(\mathrm{TXA}_{2}\right)$ [10]. The imbalance between the release of relaxing and contractile factors leads to endothelial dysfunction, affecting vascular tone [11]. As the endothelium plays a key role in the maintenance of vascular tone, a study of the effect of probiotics on endothelial function is valuable. Regarding the effect of specific probiotics on the circulatory system, there are few studies focused on vascular reactivity. Recent studies showed an improvement in endothelial function with probiotics (VSL\#3) in mesenteric arteries from portal hypertensive rats [12]. Lactobacillus coryniformis CECT 5711 also demonstrated to exert an endothelial-protective effect by increasing NO bioavailability in obese mice [13]. However, there are few studies assessing the long-term vascular effects of dietary supplementation with potential probiotic strains. Accordingly, the aim of the present study was to determine whether oral supplementation of $B$. pseudocatenulatum CECT 7765 during 14 weeks in obese mice could modulate vascular response to $\mathrm{KCl}$, $\mathrm{TXA}_{2}$ analogue and noradrenaline, focusing on the release of $\mathrm{NO}$ induced by noradrenaline. We also studied the response to acetylcholine and sodium nitroprusside (SNP) in aortic segments from obese mice fed or not the bifidobacteria. Finally, we analyze whether gene expression of eNOS could be altered by obesity or bifidobacteria administration.

\section{Material and Methods}

\section{Bacterial strain and culture conditions}

B. pseudocatenulatum CECT 7765 was grown in MRS broth (Scharlau, Barcelona, Spain) supplemented with $0.05 \%(w / v)$ cysteine (MRS-C Sigma, St. Louis,
$\mathrm{MO}$ ), and incubated at $37^{\circ} \mathrm{C}$ for $22 \mathrm{~h}$ under anaerobic conditions (AnaeroGen, Oxoid, Basingstoke, UK). Cells were harvested $(6000 \times \mathrm{g}$ for $15 \mathrm{~min})$, washed twice in phosphate buffered saline (PBS, $130 \mathrm{mM}$ sodium chloride, $10 \mathrm{mM}$ sodium phosphate, $\mathrm{pH} 7.4$ ), and re-suspended in $10 \%$ skimmed milk for oral administration to mice. Aliquots of these suspensions were frozen in liquid nitrogen and stored at $-80^{\circ} \mathrm{C}$ until used. The number of live cells after freezing and thawing was determined by colony-forming unit (CFU) counting on MRS-C agar following $48 \mathrm{~h}$ incubation. More than $90 \%$ cells were alive upon thawing and no significant differences were found during storage (2 months). One fresh aliquot was thawed each new experiment to avoid variability in the viability of cultures.

\section{Animals, diets and experimental design}

Animal experiments were carried out in strict accordance with the recommendations in the Guide for the Care and Use of Laboratory Animals of University of Valencia (Central Service of Support to Research [SCSIE], University of Valencia, Spain) and the protocol was approved by its Ethic Committee (approval ID A1245740259386). Adult (age 6-8 week) male wild-type C57BL-6 mice were purchased from Harlan Laboratories. During the adaptation period (7 days), ten animals were housed in each stainless-steel cage in a temperature-controlled $\left(23^{\circ} \mathrm{C}\right)$ room with a 12-h light/dark cycle and $40-50 \%$ relative humidity. Then, mice were randomly divided into three groups ( $\mathrm{n}=10$ mice per group) as follows: (1) a control group, receiving a standard diet (SD); (2) an obese group, receiving a high-fat diet (HFD); and (3) an obese group receiving the HFD and a daily dose of $1.0 \times 10^{9}$ CFU B. pseudocatenulatum CECT 7765 by oral gavage (HFD+Bif). In order to control for the possible stress induced by the gavage procedure, Groups 1 and 2 received the vehicle by daily gavage. To induce obesity, mice were switched from the SD (CA.170481-AIN-76A Purified Diet-Rats/Mice, Harlan Laboratories, Madison, WI 53744-4220) administered during the adaptation period to all mice, to a HFD (TD.06414 - Adjusted Calories Diet - 60/Fat, Harlan Laboratories, Madison, WI 53744-4220) for 14 weeks. The HFD provided $18.4 \% \mathrm{kcal}$ as protein, $21.3 \% \mathrm{kcal}$ as carbohydrate and $60.3 \% \mathrm{kcal}$ as fat $(5.1$ $\mathrm{kcal} / \mathrm{g}$ ), whereas the SD provided $18.8 \% \mathrm{kcal}$ as protein, $68.8 \% \mathrm{kcal}$ as carbohydrate and $12.4 \% \mathrm{kcal}$ as fat $(3.8 \mathrm{kcal} / \mathrm{g})$. Therefore, there was an increase in fat at expenses of a reduction in carbohydrates in the HFD. Mice had free access to feed and sterile water.

Body weight was measured once a week and, at the end of study. Mice were sacrificed 14 weeks after beginning the diet. Blood was withdrawn by 
intra-cardiac puncture under anesthesia and centrifuged to obtain the serum that was stored at $-20^{\circ} \mathrm{C}$.

\section{Determination of serum leptin and insulin concentration}

Serum leptin concentration was determined by the Assay Max Mouse Leptin ELISA kit (Assay pro, LLC; Ireland) with a sensitivity threshold of $0.3 \mathrm{ng} / \mathrm{ml}$ and insulin was measured using a Rat/ Mouse ELISA kit (Merck Millipore, Germany) with a sensitivity threshold of $0.2 \mathrm{ng} / \mathrm{ml}$, according to the manufacturer's instructions.

\section{Organ bath experiments}

Aortic segments were immediately placed in chilled Krebs-Henseleit solution, and rings $3 \mathrm{~mm}$ long were cut for isometric tension recording. Two stainless steel L-shaped pins $100 \mu \mathrm{m}$ diameter were introduced through the lumen of the vessel. One pin was fixed to the wall of the organ bath and the other was connected to a force-displacement transducer (Grass FT03). Changes in isometric force were recorded on a Macintosh computer using the Chart $v$ 7/s software and MacLab/8e data acquisition system (AD Instruments). Each ring was suspended in a $4 \mathrm{ml}$ bath containing modified Krebs-Henseleit solution containing (in mmol/l) $\mathrm{NaCl}, 115 ; \mathrm{KCl}, 4.6$; $\mathrm{MgCl}_{2} \cdot 6 \mathrm{H}_{2} \mathrm{O}, 1.2 ; \mathrm{CaCl}_{2}, 2.5 ; \mathrm{NaHCO}_{3}$, 25; glucose 11.1 and disodium EDTA, 0.01. The solution was equilibrated with $95 \% \mathrm{O}_{2}$ and $5 \% \mathrm{CO}_{2}$ to obtain a $\mathrm{pH}$ of 7.3-7.4. Temperature was held at $37^{\circ} \mathrm{C}$. The optimal resting tension was $1 \mathrm{~g}$. The arterial rings were allowed to attain a steady level of tension during a $1 \mathrm{~h}$ accommodation period before testing.

We evaluated the contractile capacity of vascular smooth muscle by administration of $\mathrm{KCl}(60 \mathrm{mM})$. Cumulative concentration-response curves to thromboxane analogue U46619 $\left(10^{-10}-3 \times 10^{-7} \mathrm{M}\right)$ and noradrenaline $\left(10^{-9}-3 \times 10^{-7} \mathrm{M}\right)$ were performed in arteries from three studied groups. The response to noradrenaline $\left(10^{-9}-3 \times 10^{-7} \mathrm{M}\right)$ was studied in the absence (control response) and in the presence of NG-nitro-L-arginine methyl ester (L-NAME, $10^{-4} \mathrm{M}$ ) to inhibit the production of NO. To evaluate the endothelial dependent an independent vasodilation, we administrated acetylcholine $\left(10^{-8}-3 \times 10^{-6} \mathrm{M}\right)$ and SNP $\left(10^{-9}-3 \times 10^{-7} \quad \mathrm{M}\right)$ respectively in arteries precontracted with noradrenaline. After a stable contraction was obtained, concentration-response curves were recorded. All drugs and reagents used in organ bath experiments were purchased from Sigma Chemical Co. (St Louis, MO, USA).

\section{Real-time polymerase chain reaction analyses}

Aortic segments were collected from each mouse into an RNAlater solution (Ambion, Austin, TX, USA), an RNAstabilization reagent, following the manufacturer's instructions. Total RNA was extracted with Tripure isolation reagent (Roche Molecular Biochemicals, Basel, Switzerland), and concentration and integrity were assessed in RNA 6000 Nano Labchips using Agilent 2100 Bioanalyzer (Agilent Technologies, Foster City, CA, USA). Ready-to-use primers and probes from the assay-on-demand service of Applied Biosystems were used for the quantification of selected target gene: eNOS (Mm00435217_m1) and endogenous reference gene $\beta$-actin (Mm00607939_s1). RNA samples were reverse-transcribed using random hexamers and MultiScribe reverse transcriptase (Applied Biosystems). After complementary DNA synthesis, real-time polymerase chain reaction (RT-PCR) was carried out using the ABI Prism 7900HT Sequence Detection System (Applied Biosystems). Samples were run in triplicate, and expression changes were generated by calculating 2-DDCT [14].

\section{Data analysis}

Values are expressed as mean \pm standard error of the mean. Relaxation was expressed as a percentage of inhibition of noradrenaline-induced contraction. Concentrations of agonist producing half-maximal effect $\left(E_{50}\right)$ were determined from individual concentration-response curves by nonlinear regression analysis and were expressed as $\mathrm{pD}_{2}(-\log$ $\mathrm{EC}_{50}$ ). Differences between groups were determined with ANOVA and post hoc Bonferroni's test. Statistical significance was accepted at $p<0.05$.

\section{Results}

\section{Effect of B. pseudocatenulatum CECT 7765 on body weight gain and plasma levels of leptin and insulin}

The administration of B. pseudocatenulatum CECT 7765 significantly reduced relative body weight gain by approximately $30 \%(p<0.05)$ in the HFD group at the end of the intervention. B.pseudocatenulatum CECT 7765 administration reduced the HFD-increased leptin $(p<0.05)$ and fasting insulin levels $(p<0.05)$ (Table 1).

\section{Contractile response}

Contractile response to $\mathrm{KCl} 60 \mathrm{mM}$ was lower in aortic segments from HFD group $(551 \pm 31 \mathrm{mg}$ in SD group vs $365 \pm 31 \mathrm{mg}$ in HFD group $p<0.05$ ). Bifidobacteria administration reversed this effect equating the value to the control group $(508 \pm 35 \mathrm{mg}$ in HFD+Bif group).

Contractile response to the $\mathrm{TXA}_{2}$ analogue U46619 was lower in HFD group compared with SD 
group. This effect was reversed with bifidobacteria administration (Fig. 1, Table 2). Noradrenaline produced concentration-dependent contractions, which were of lower magnitude in HFD group compared to SD group. This effect was reversed with bifidobacteria administration (Fig. 2A, Table 3).

Table 1. Weight gain and serum hormonal parameters in different mouse groups after 14 weeks of dietary intervention.

\begin{tabular}{llll}
\hline $\begin{array}{l}\text { Experimental } \\
\text { groups }\end{array}$ & $\begin{array}{l}\text { Body weight gain } \\
(\%)\end{array}$ & Insulin $(\mathrm{ng} / \mathrm{ml})$ & Leptin $(\mathrm{ng} / \mathrm{ml})$ \\
\hline SD group & $35.03 \pm 4.02$ & $0.47 \pm 0.04$ & $9.29 \pm 0.37$ \\
HFD group & $62.30 \pm 4.39^{*}$ & $2.09 \pm 0.29^{*}$ & $36.53 \pm 2.70^{*}$ \\
HFD+Bif group & $44.00 \pm 2.66^{\#}$ & $1.05 \pm 0.21^{* \#}$ & $29.78 \pm 2.57^{* \#}$ \\
\hline
\end{tabular}

SD group: control mice receiving a standard diet; HFD group: obese mice receiving a high-fat diet; HFD+Bif group: obese mice receiving HFD and a daily dose of $1 \mathrm{x}$ $10^{9}$ CFU B. pseudocatenulatum CECT 7765 by gavage during 14 weeks. Data are expressed as mean \pm standard error of the mean of each mouse group $(n=10$ per group).

Significant differences were established by ANOVA and post hoc Bonferroni's test at ${ }^{*} p<0.05$ versus SD group and ${ }^{*} p<0.05$ versus HFD group.

Table 2. $\mathrm{pD}_{2}$ values and maximal responses (Emax) elicited by thromboxane analogue, U-46619 in aortic segments from different mouse groups.

\begin{tabular}{lll}
\hline $\mathrm{U}-46619$ & $\mathrm{pD}_{2}$ & Emax $(\mathrm{mg})$ \\
\hline SD group & $8.01 \pm 0.05$ & $1649 \pm 111$ \\
HFD group & $7.64 \pm 0.05^{*}$ & $1196 \pm 87^{*}$ \\
HFD+Bif group & $7.75 \pm 0.06$ & $1531 \pm 135^{\#}$
\end{tabular}

SD group: control mice receiving a standard diet; HFD group: obese mice receiving a high-fat diet; $\mathrm{HFD+Bif}$ group: obese mice receiving HFD and a daily dose of $1 \mathrm{x}$ $10^{9} \mathrm{CFU}$ B. pseudocatenulatum CECT 7765 by gavage during 14 weeks.

$\mathrm{pD}_{2},-\log \mathrm{mol} / \mathrm{L}$ of substance causing $50 \%$ of the maximal contraction; Emax, maximal contraction. Data are expressed as mean \pm standard error of the mean of each mouse group ( $\mathrm{n}=8$ per group).

Significant differences were established by ANOVA and post hoc Bonferroni's test at ${ }^{*} p<0.05$ versus SD group and ${ }^{*} p<0.05$ versus HFD group.

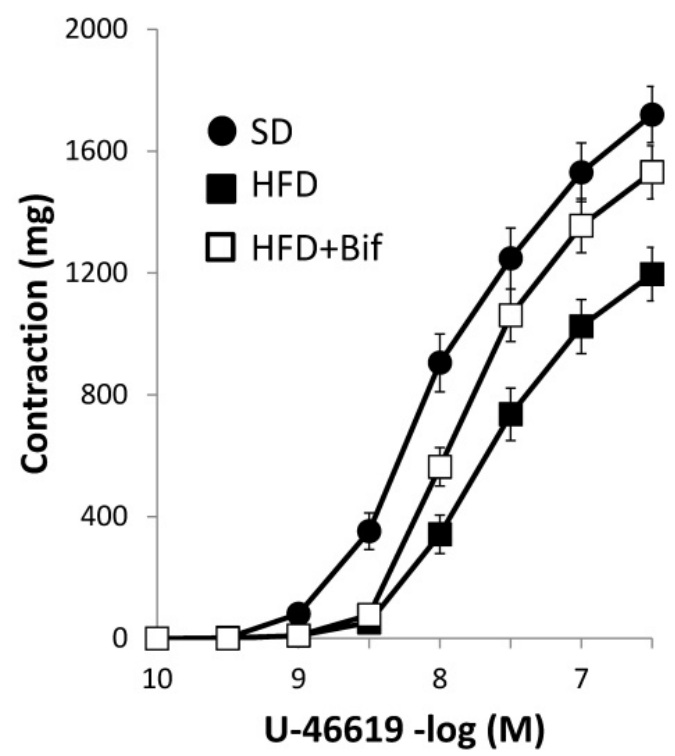

Figure 1. Concentration-response curves to thromboxane $A_{2}$ (TXA 2 ) analogue U-46619 in aortic segments from mice receiving a standard diet (SD group); a high fat diet (HFD group) and a high fat diet plus a daily dose of $1 \times 10^{9}$ CFU B. pseudocatenulatum CECT 7765 by gavage during 14 weeks (HFD+Bif group). Values are mean \pm standard error of the mean ( $n=8$ per group).

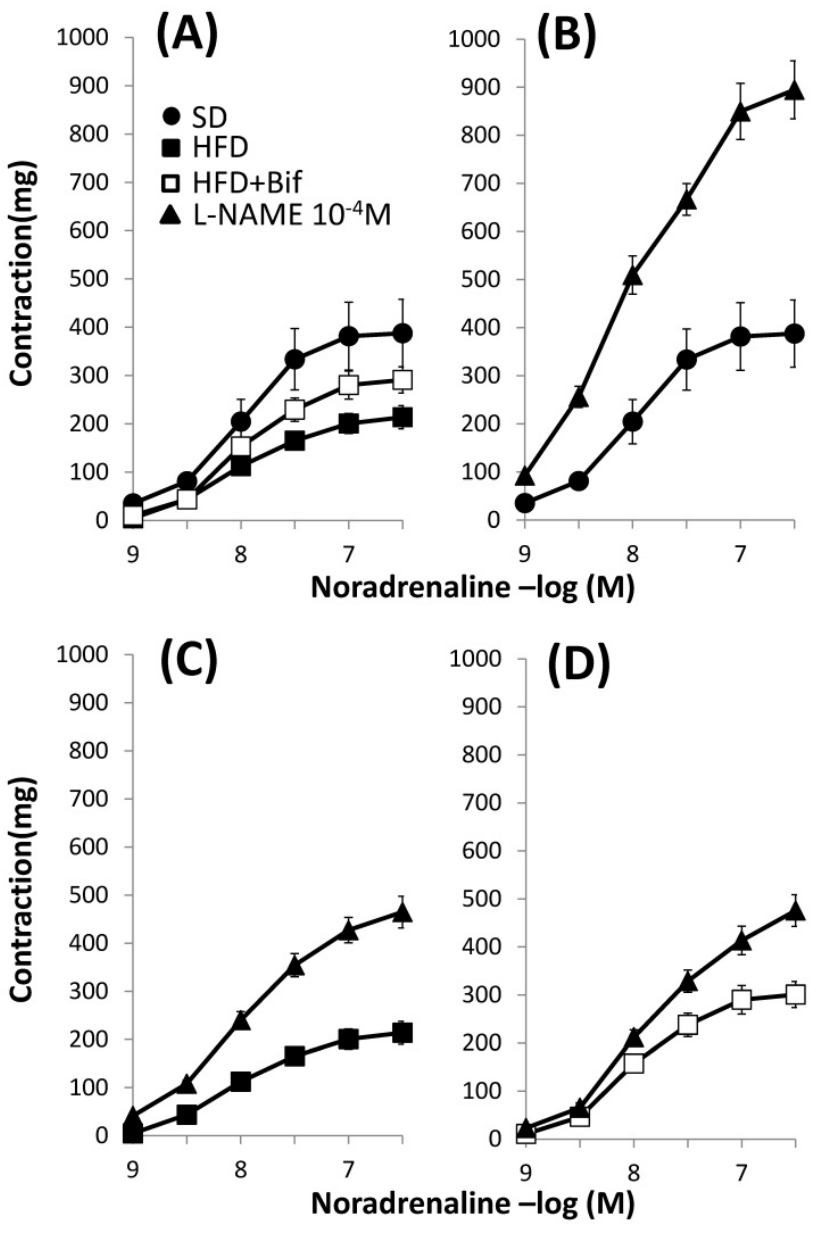

Figure 2. Concentration-response curves to noradrenaline in aortic segments. (A): Comparative among the three studied groups: mice receiving a standard diet (SD group); a high fat diet (HFD group) and a high fat diet plus a daily dose of $1 \times 10^{9}$ CFU B. pseudocatenulatum CECT 7765 by gavage during 14 weeks (HFD+Bif group). Effects of L-NAME (10-4 M) in the concentration-response curve to noradrenaline in aortic segments from mice receiving $(B)$ a standard diet (SD group); (C) a high fat diet (HFD group) and (D) a high fat diet plus a daily dose of $1 \times 10^{9}$ CFU $B$. pseudocatenulatum CECT 7765 by gavage during 14 weeks (HFD+Bif group). Values are mean \pm standard error of the mean $(n=8$ per group).

Table 3. $\mathrm{pD}_{2}$ values and maximal responses (Emax) elicited by noradrenaline in the absence and in the presence of L-NAME in mouse aortic segments from the three studied groups.

\begin{tabular}{lll}
\hline Noradrenaline & $\mathrm{pD}_{2}$ & Emax $(\mathrm{mg})$ \\
\hline SD & $8.01 \pm 0.06$ & $388 \pm 70^{\$}$ \\
SD + L-NAME & $8.11 \pm 0.03$ & $895 \pm 60$ \\
HFD & $8.03 \pm 0.05$ & $214 \pm 24^{* \$}$ \\
HFD + L-NAME & $8.00 \pm 0.03$ & $465 \pm 33$ \\
HFD+Bif & $8.06 \pm 0.06$ & $301 \pm 27^{\#}$ \\
HFD+Bif + L-NAME & $7.89 \pm 0.03$ & $476 \pm 33$
\end{tabular}

SD group: control mice receiving a standard diet; HFD group: obese mice receiving a high-fat diet; HFD+Bif group: obese mice receiving HFD and a daily dose of $1 \mathrm{x}$ $10^{9}$ CFU B. pseudocatenulatum CECT 7765 by gavage during 14 weeks. $\mathrm{pD}_{2},-\log \mathrm{mol} / \mathrm{L}$ of substance causing $50 \%$ of the maximal contraction; Emax, maximal contraction; L-NAME, NG-nitro-L-arginine methyl ester. Data are expressed as mean \pm standard error of the mean of each mouse group $(n=8$ per group).

Significant differences were established by ANOVA and post hoc Bonferroni's test at ${ }^{*} p<0.05$ versus SD group, ${ }^{*} p<0.05$ versus HDF $s p<0.05$ compared with L-NAME treatment in the same group. 


\section{Effect of NOS inhibitor on noradrenaline induced contractions}

The release of NO in response to noradrenaline was characterized as the difference between Emax to noradrenaline in the presence and in the absence of the NO synthase inhibitor, L-NAME. Incubation with L-NAME increased in a similar manner the maximal contractile response to noradrenaline in arteries from both SD and HFD groups $(129 \pm 44 \%$ in SD group vs $114 \pm 17 \%$ in HFD group, Fig. $2 \mathrm{~B}$ and $2 \mathrm{C}$, Table 3 ) indicating that our obesity model does not alter the release of $\mathrm{NO}$ in response to noradrenaline. The increment was lower in arteries from those mice receiving a daily dose of bifidobacteria indicating that this bacterial strain diminishes the release of $\mathrm{NO}$ $(114 \pm 17 \%$ in HFD group vs $54 \pm 13 \%$ in HFD+Bif group, $\mathrm{p}<0.05$, Fig. 2D).

\section{Vasodilator response}

Acetylcholine $\left(10^{-8}-3 \times 10^{-6} \mathrm{M}\right)$ caused a greater relaxation response in aortic segments from HFD group compared to SD group $(69 \pm 4 \%$ and $46 \pm 3 \%$ for the HFD and SD group respectively $p<0.05 ; n=8$ ). Group receiving a daily dose of bifidobacteria showed a significant lesser relaxation (Fig. 3A, Table 4). Incubation with L-NAME completely blocked the response to acetylcholine (data not shown).

The concentration-response curve to sodium nitroprusside (SNP) $\left(10^{-9}-3 \times 10^{-7} \mathrm{M}\right)$ was significantly displaced 2.9 times to the left in a parallel manner in HFD group compared to SD group, $\mathrm{p}<0.05$ (Fig. 3B, Table 4). Relaxation to SNP remained unchanged in the bifidobacteria fed group, so this bacterial strain does not modify ability of vascular smooth muscle to dilate in response to NO.
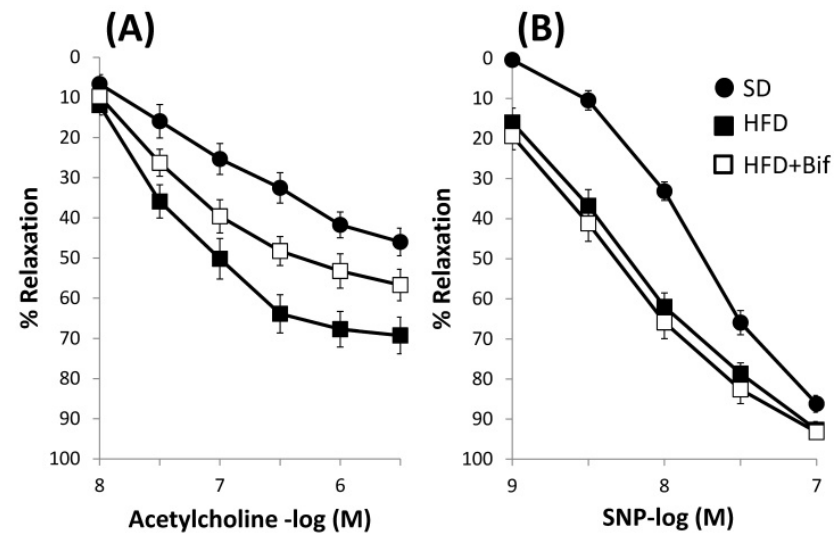

Figure 3. Concentration-response curves to $(A)$ acetylcholine and $(B)$ sodium nitroprusside (SNP) in aortic segments from mice receiving a standard diet (SD group); a high fat diet (HFD group) and a high fat diet plus a daily dose of $1 \times 109$ CFU B. pseudocatenulatum CECT 7765 by gavage during 14 weeks (HFD+Bif group). Relaxation is expressed as a percentage of the contraction in response to noradrenaline. Values are mean \pm standard error of the mean $(n=8$ per group).
Table 4. Concentration-response curves to acetylcholine (Ach) and sodium nitroprusside (SNP) on aortic rings from the three studied groups. Relaxation is expressed as a percentage of the contraction in response to noradrenaline.

\begin{tabular}{lllll}
\hline $\begin{array}{l}\text { Experimental } \\
\text { groups }\end{array}$ & Ach pD2 & Ach Emax (\%) & SNP pD2 & SNP Emax (\%) \\
\hline SD & $7.06 \pm 0.13$ & $46 \pm 3$ & $7.83 \pm 0.05$ & $86 \pm 2$ \\
HFD & $7.46 \pm 0.07^{*}$ & $69 \pm 4^{*}$ & $8.30 \pm 0.06^{*}$ & $93 \pm 2^{*}$ \\
HFD+Bif & $7.29 \pm 0.11$ & $57 \pm 5 \#$ & $8.46 \pm 0.07^{*}$ & $93 \pm 1^{*}$ \\
\hline
\end{tabular}

SD group: control mice receiving a standard diet; HFD group: obese mice receiving a high-fat diet; HFD+Bif group: obese mice receiving HFD and a daily dose of $1 \mathrm{x}$ $10^{9} \mathrm{CFU}$ B. pseudocatenulatum CECT 7765 by gavage during 14 weeks. $\mathrm{pD}_{2},-\log$ $\mathrm{mol} / \mathrm{L}$ of substance causing $50 \%$ of the maximal contraction; Emax, maximal contraction. Data are expressed as mean \pm standard error of the mean of each mouse group ( $\mathrm{n}=8$ per group).

Significant differences were established by ANOVA and post hoc Bonferroni's test at ${ }^{*} p<0.05$ versus SD group and $\# p<0.05$ versus HFD group.

\section{mRNA expression of eNOS}

We performed real-time RT-PCR on aortic segments from SD, HFD and HFD+Bif group. The mRNA expression of eNOS was similar in SD and HFD group and there was a decreased mRNA expression of eNOS in aorta from HFD+Bif group of five-fold compared with SD group and six-fold compared with HFD group (Fig. 4).

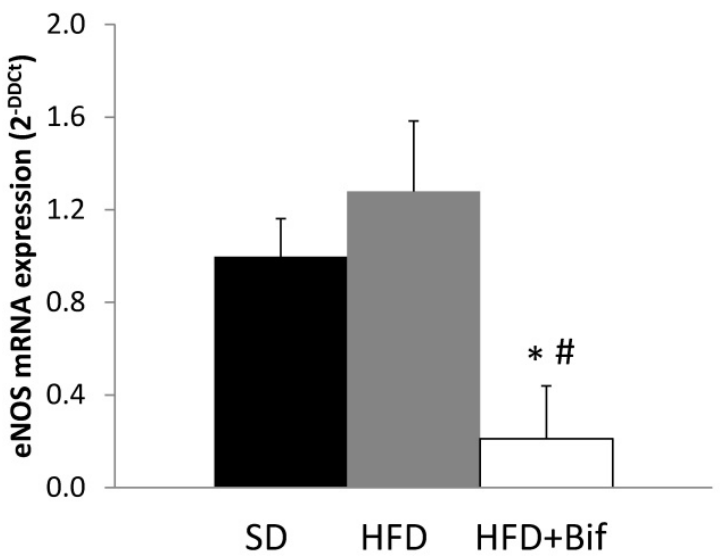

Figure 4. Changes in messenger RNA (mRNA) expression of endothelial nitric oxide synthase (eNOS) in aortic segments reported as fold changes relative to SD group. SD: standard diet group $(n=8)$; HFD: high fat diet group $(n=8)$; HFD+Bif: high fat diet group receiving a daily dose of $1 \times 10^{9}$ CFU $B$. pseudocatenulatum CECT 7765 by gavage during 14 weeks $(n=8)$. $*_{p}<0.05$ versus SD group. $\# p<0.05$ versus HFD group.

\section{Discussion}

This study evaluates the vascular effects of a supplemented diet with B. pseudocatenulatum CECT 7765 , which was previously demonstrated to improve metabolic and immunological alterations in obese mice [5-7]. Our results showed an altered vascular reactivity in the obesity model and the administration of B. pseudocatenulatum CECT 7765 to obese mice during 14 weeks reversed these effects. In addition, administration of bifidobacteria also decreases eNOS expression. Therefore, our results demonstrate that 
the administration of B. pseudocatenulatum CECT 7765 might improve vascular dysfunction caused by HFD-induced obesity.

\section{Contractile response}

Vascular contractile response in obesity is not homogeneous. There are studies demonstrating an increase [15], no change [16] or a decrease in reactivity to agonist vasoconstrictors [17]. Differences in pharmacological responses of blood vessels might be receptor-mediated or due to nonspecific responses of smooth muscle. $\mathrm{KCl}$-induced contraction occurs by a mechanism independent of receptor and is used as an index of vascular smooth muscle contraction ability [18]. Our results show that HFD-induced obesity decreases vascular response to $\mathrm{KCl}$ in aortic segments. Bifidobacteria administration reverses the hyporesponsiveness to $\mathrm{KCl}$ in obese group. At $60 \mathrm{mM}$ $\mathrm{KCl}$ one can assume that the vascular muscle is depolarized. $\mathrm{KCl}$-induced constriction is mediated primarily via depolarization-induced opening of voltage-gated $\mathrm{Ca}^{2+}$ channels and influx of extracellular $\mathrm{Ca}^{2+}$ [18]. Accordingly, HFD-induced obesity may affect voltage-gated $\mathrm{Ca}^{2+}$ channels or distal mechanisms that respond to $\mathrm{Ca}^{2+}$ influx. Our experiments also showed a lower response to U-46619 in aortic segments from obese mice. This effect was reversed with bifidobacteria supplementation. Fat intake may affect vascular response and receptor expression of vasoactive factors. Previous studies have reported increased TXA 2 plasma levels in obese hyperlipidemic rats [19] and increases in $\mathrm{TXA}_{2}$ receptor gene expression in obese mice [15]. Activation of thromboxane-prostanoid (TP) receptors in smooth muscle cells by TXA $\mathrm{T}_{2}$ produced an increase in intracellular $\mathrm{Ca}^{2+}$ levels and trigger vasoconstriction [20]. In view of these results, we hypothesize that vascular smooth muscle from obese mice has less capacity to contract due to a mechanism related to calcium, since the response to $\mathrm{KCl}$ and $\mathrm{TXA}_{2}$ is decreased in HFD-induced obesity. Although obesity is related to excess of energy and macronutrient intake, it does not rule out the presence of micronutrient deficiencies, among which calcium is found [21]. The effects of calcium absorption are associated with intestinal microbiota modulation [22] so a bacterial strain that improves calcium homeostasis could be beneficial in obesity. In this sense, our results showed the ability of $B$. pseudocatenulatum CECT 7765 to increase constrictor response to $\mathrm{KCl}$ and $\mathrm{TXA}_{2}$ suggesting an action on voltage-gated $\mathrm{Ca}^{2+}$ channels or distal mechanisms that respond to influx of $\mathrm{Ca}^{2+}$. Studies in aortic smooth muscle cell culture and cardiomyocytes have shown that some probiotic products increase intracellular
$\mathrm{Ca}^{2+}$ concentration resulting in contractility of blood vessels and myocardium [23]. In addition, previous experiments have shown that some probiotics could increase plasma calcium levels by improving calcium bioavailability [24] solubility [25] and absorption [26] as well as diminishing urinary excretion [27]. Therefore, increased contractile response to $\mathrm{KCl}$ and $\mathrm{TXA}_{2}$ in mice receiving a daily dose of $B$. pseudocatenulatum CECT 7765 could be due to augmented $\mathrm{Ca}^{2+}$ influx or increased contractile myofilaments sensitivity to $\mathrm{Ca}^{2+}$.

Response to noradrenaline was lower in obese group and bifidobacteria supplementation reversed this effect. Noradrenaline produces contraction by activating vascular a-adrenergic receptors, which in turn stimulate phospholipase $\mathrm{C}$ and increase intracellular $\mathrm{Ca}^{2+}$ availability. This contraction can be attenuated by endothelial NO release [28]. L-NAME augmented contractile response to noradrenaline in aortic segments from both control and obese mice. This effect is attributed to inhibition by L-NAME of the depressant influence of endothelial NO released by noradrenaline through a-adrenoceptors stimulation on endothelial cells [29] or by an indirect mechanism involving a signal conducted from smooth muscle stimulation to adjacent endothelial cells [30]. Therefore, removal of the relaxant effect of nitric oxide would result in an increased contraction to noradrenaline, an effect that has been shown in several experiments $[28,29,31]$. Since inhibition of NO release with L-NAME is similar in arteries from both SD and HFD groups, our results indicate that the obesity model did not modify eNOS activity. Accordingly, eNOS mRNA expression is similar in SD and HFD group. The increase in contractile response to noradrenaline in the presence of L-NAME was less in arteries from mice receiving a daily dose of $B$. pseudocatenulatum CECT 7765 indicating that the bacterial strain decreases eNOS activity. Moreover, we found significantly decreased eNOS mRNA levels in aortic segments from HFD group fed the bifidobacteria compared to obese fed placebo indicating a lower $\mathrm{NO}$ synthesis in obese mice receiving bifidobacteria supplementation.

\section{Vasodilator response}

Acetylcholine induced endothelium-dependent relaxation trough activation of muscarinic receptors in aortic segments from all studied groups. Relaxation was higher in obese group than in SD group. In both groups, L-NAME completely abolished relaxation to acetylcholine indicating that NO mediates this response. So, augmented vasodilation in obese group could be attributed to an increase of NO release and this is in contrast with previous studies which have 
reported a decrease of endothelium-dependent relaxation to vasodilators in obesity [32-35]. However an increase of eNOS activation [36] and improvement of endothelial-L-arginine/NO pathway have been previously described [16]. These effects have been related with hyperinsulinemia and hyperleptinemia associated with obesity since both insulin and leptin increase endothelial NO production [16]. In our obesity model, increased plasma levels of insulin and leptin may enhance NO release explaining the greater relaxation to acetylcholine in obese group. It is also possible that increased relaxing response to acetylcholine in HFD-induced obesity can be due to an enhanced vascular smooth muscle sensitivity to NO. This possibility is based on relaxation to sodium nitroprusside, an exogenous nitric oxide donor, was of greater magnitude in arteries from obese mice. Our results also demonstrate a diminished relaxation to acetylcholine in aortic segments from group receiving a daily dose of bifidobacteria. This is probably due to a decrease in the production of NO. This effect is consistent with a decrease in eNOS expression due to bifidobacteria administration. Studies involving effects of probiotic treatment on the acetylcholine-induced NO are inconclusive. Probiotic treatment has been reported to enhance $\mathrm{NO}$ bioavailability $[13,37]$ or has no effect on the release of $\mathrm{NO}$ in response to acetylcholine [12,38]. These discrepancies may be due to the differences in the probiotic strains tested as well as the different vascular bed studied. We also observed that the response to sodium nitropusside is not affected by bifidobacteria administration suggesting that bifidobacteria does not affect vascular smooth muscle sensitivity to NO.

\section{Conclusion}

Obesity induced by HFD decreases vasoconstrictor response to different agonists and enhances vasodilator response. B. pseudocatenulatum CECT 7765 restores altered vascular function induced by obesity by reducing NO release. However, these effects are bacterial strain-dependent and care must be taken in extrapolating data obtained from one organism to another. Because our findings are limited to study aortic reactivity in mice, a link between our results and the clinical studies should be further investigated. Despite these considerations, our results shown a direct link between microbiota and vascular effects in a model of obesity induced by high fat diet.

\section{Acknowledgments}

This work was supported by grant AGL2014-52101-P from the Spanish Ministry of Economy and Competitiveness (MINECO).

\section{Competing Interests}

The authors have declared that no competing interest exists.

\section{References}

1. Mauricio MD, Aldasoro M, Ortega J, Vila JM. Endothelial dysfunction in morbid obesity. Curr Pharm Des. 2013;19:5718-29.

2. Park YH, Kim JG, Shin YW, Kim SH, Whang KY. Effect of dietary inclusion of Lactobacillus acidophilus ATCC 43121 on cholesterol metabolism in rats. J Microbiol Biotechnol. 2007 ; 17:655-62.

3. Sato M, Uzu K, Yoshida T, Hamad EM, Kawakami H, Matsuyama H, et al. Effects of milk fermented by Lactobacillus gasseri SBT2055 on adipocyte size in rats. Br J Nutr. 2008 ;99:1013-7.

4. Xiao JZ, Kondo S, Takahashi N, Miyaji K, Oshida K, Hiramatsu A, et al. Effects of milk products fermented by Bifidobacterium longum on blood lipids in rats and healthy adult male volunteers. J Dairy Sci. 2003 Jul;86(7):2452-61.

5. Cano PG, Santacruz A, Trejo FM, Sanz Y. Bifidobacterium CECT 7765 improves metabolic and immunological alterations associated with obesity in high-fat diet-fed mice. Obes Silver Spring Md. 2013;21:2310-21.

6. Moya-Pérez A, Romo-Vaquero M, Tomás-Barberán F, Sanz Y, García-Conesa M-T. Hepatic molecular responses to Bifidobacterium pseudocatenulatum CECT 7765 in a mouse model of diet-induced obesity. Nutr Metab Cardiovasc Dis NMCD. 2014;24:57-64

7. Moya-Pérez A, Neef A, Sanz Y. Bifidobacterium pseudocatenulatum CECT 7765 Reduces Obesity-Associated Inflammation by Restoring the Lymphocyte-Macrophage Balance and Gut Microbiota Structure in High-Fat Diet-Fed Mice. PloS One. 2015;10(7):e0126976.

8. Franklin BA, Kahn JK. Delayed progression or regression of coronary atherosclerosis with intensive risk factor modification. Effects of diet, drugs, and exercise. Sports Med Auckl NZ. 1996;22:306-20.

9. Ross R. The pathogenesis of atherosclerosis: a perspective for the 1990s. Nature. 1993;362:801-9.

10. Schiffrin EL. A critical review of the role of endothelial factors in the pathogenesis of hypertension. J Cardiovasc Pharmacol. 2001;38 Suppl 2:S3-6.

11. Félétou M, Vanhoutte PM. Endothelial dysfunction: a multifaceted disorder (The Wiggers Award Lecture). Am J Physiol Heart Circ Physiol. 2006;291:H985-1002

12. Rashid SK, Idris-Khodja N, Khodja NI, Auger C, Alhosin M, Boehm N, et al. Probiotics (VSL\#3) prevent endothelial dysfunction in rats with portal hypertension: role of the angiotensin system. PloS One. 2014;9(5):e97458.

13. Toral M, Gómez-Guzmán M, Jiménez R, Romero M, Sánchez M, Utrilla MP, et al. The probiotic Lactobacillus coryniformis CECT5711 reduces the vascular pro-oxidant and pro-inflammatory status in obese mice. Clin Sci Lond Engl 1979. 2014;127:33-45.

14. Livak KJ, Schmittgen TD. Analysis of relative gene expression data using real-time quantitative PCR and the 2(-Delta Delta C(T)) Method. Methods San Diego Calif. 2001;25:402-8.

15. Traupe T, Lang M, Goettsch W, Münter K, Morawietz H, Vetter W, et al. Obesity increases prostanoid-mediated vasoconstriction and vascular thromboxane receptor gene expression. J Hypertens. 2002;20:2239-45.

16. Nascimento TB, Baptista R de FF, Pereira PC, Campos DHS, Leopoldo AS, Leopoldo APL, et al. Vascular alterations in high-fat diet-obese rats: role of endothelial L-arginine/NO pathway. Arq Bras Cardiol. 2011;97:40-5.

17. Jerez S, Scacchi F, Sierra L, Karbiner S, de Bruno MP. Vascular hyporeactivity to angiotensin II and noradrenaline in a rabbit model of obesity. J Cardiovasc Pharmacol. $2012 ; 59: 49-57$.

18. Hall J, Jones TH, Channer KS, Jones RD. Mechanisms of agonist-induced constriction in isolated human mesenteric arteries. Vascul Pharmacol. 2006;44:427-33.

19. Khan SF, et al. Dual effect of atorvastatin on endothelium; reduction in LDL and TXA2 levels but unaltered HCY levels in obese hyperlipidemic rats. Prof Med J. 2015;9:1496-1202.

20. Alexander RW, Griendling KK. Signal transduction in vascular smooth muscle. J Hypertens Suppl Off J Int Soc Hypertens. 1996;14:S51-54.

21. Sánchez A, Rojas P, Basfi-Fer K, Carrasco F, Inostroza J, Codoceo J, et al. Micronutrient Deficiencies in Morbidly Obese Women Prior to Bariatric Surgery. Obes Surg. 2016 ;26:361-8.

22. Gomes JMG, Costa JA, Alfenas RC. Could the beneficial effects of dietary calcium on obesity and diabetes control be mediated by changes in intestinal microbiota and integrity? Br J Nutr. 2015;114:1756-65.

23. Sobol CV, Korotkov SM, Belostotskaya GB, Nesterov VP. The influence of probiotics and probiotic product on respiration of mitochondria and intracellular calcium signal in cells of cardiovascular system. Biochem Mosc Suppl Ser Membr Cell Biol. 2013;7:294-301.

24. Bergillos-Meca T, Navarro-Alarcón M, Cabrera-Vique C, Artacho R, Olalla M, Giménez R, et al. The probiotic bacterial strain Lactobacillus fermentum D3 increases in vitro the bioavailability of $\mathrm{Ca}, \mathrm{P}$, and $\mathrm{Zn}$ in fermented goat milk. Biol Trace Elem Res. 2013;151:307-14

25. Parvaneh K, Jamaluddin R, Karimi G, Erfani R. Effect of probiotics supplementation on bone mineral content and bone mass density. ScientificWorldJournal. 2014;2014:595962. 
26. Gilman J, Cashman KD. The effect of probiotic bacteria on transepithelial calcium transport and calcium uptake in human intestinal-like Caco-2 cells. Curr Issues Intest Microbiol. 2006 ; 7:1-5.

27. Ohlsson C, Engdahl C, Fåk F, Andersson A, Windahl SH, Farman HH, et al. Probiotics protect mice from ovariectomy-induced cortical bone loss. PloS One. 2014;9(3):e92368.

28. Segarra G, Lluch P, Mauricio MD, Vila JM, Medina P, Martinez-León JB, et al Contractile hyporesponsiveness to norepinephrine of forearm veins in chronic renal failure. Am J Hypertens. 2006;19:818-22.

29. Angus JA, Cocks TM, Satoh K. The alpha adrenoceptors on endothelial cells. Fed Proc. $1986 ; 45: 2355-9$.

30. Dora KA, Doyle MP, Duling BR. Elevation of intracellular calcium in smooth muscle causes endothelial cell generation of NO in arterioles. Proc Natl Acad Sci US A. 1997;94:6529-34.

31. Martínez C, Vila JM, Aldasoro M, Medina P, Chuan P, Lluch S. The human deferential artery: endothelium-mediated contraction in response to adrenergic stimulation. Eur J Pharmacol. 1994 ;261:73-8.

32. Sivitz WI, Wayson SM, Bayless ML, Sinkey CA, Haynes WG. Obesity impairs vascular relaxation in human subjects: hyperglycemia exaggerates adrenergic vasoconstriction arterial dysfunction in obesity and diabetes. J Diabetes Complications. $2007 ; 21: 149-57$.

33. Steinberg HO, Chaker H, Leaming R, Johnson A, Brechtel G, Baron AD. Obesity/insulin resistance is associated with endothelial dysfunction. Implications for the syndrome of insulin resistance. J Clin Invest. 1996 ;97:2601-10.

34. Perticone F, Ceravolo R, Candigliota M, Ventura G, Iacopino S, Sinopoli F, et al. Obesity and body fat distribution induce endothelial dysfunction by oxidative stress: protective effect of vitamin C. Diabetes. 2001;50:159-65.

35. Kobayasi R, Akamine EH, Davel AP, Rodrigues MAM, Carvalho CRO, Rossoni LV. Oxidative stress and inflammatory mediators contribute to endothelial dysfunction in high-fat diet-induced obesity in mice. J Hypertens. 2010;28:2111-9.

36. Montagnani M, Chen H, Barr VA, Quon MJ. Insulin-stimulated activation of eNOS is independent of $\mathrm{Ca} 2+$ but requires phosphorylation by Akt at Ser(1179). J Biol Chem. 2001;276:30392-8.

37. Cheng C-P, Tsai S-W, Chiu CP, Pan T-M, Tsai T-Y. The effect of probiotic-fermented soy milk on enhancing the NO-mediated vascular relaxation factors. J Sci Food Agric. 2013;93:1219-25.

38. Tripolt NJ, Leber B, Blattl D, Eder M, Wonisch W, Scharnagl H, et al. Short communication: Effect of supplementation with Lactobacillus casei Shirota on insulin sensitivity, $\beta$-cell function, and markers of endothelial function and inflammation in subjects with metabolic syndrome--a pilot study. J Dairy Sci. 2013;96:89-95. 